\title{
ESTOQUES DE CARBONO E NITROGÊNIO E DENSIDADE DO SOLO EM SISTEMAS DE ADUBAÇÃO ORGÂNICA DE CAFÉ CONILON
}

\author{
Victor Maurício da Silva(1), Alex Fabian Rabelo Teixeira ${ }^{(2)}$, Jacimar Luis de Souza ${ }^{(3)}$, Gabriel \\ Pinto Guimarães ${ }^{(1)}$, Antônio Carlos Benassi ${ }^{(2)}$ e Eduardo de Sá Mendonça ${ }^{(4) *}$ \\ (1) Universidade Federal do Espírito Santo, Centro de Ciências Agrárias, Departamento de Produção Vegetal, Programa de \\ Pós-graduação em Produção Vegetal, Alegre, Espírito Santo, Brasil. \\ (2) Instituto Capixaba de Pesquisa, Assistência Técnica e Extensão Rural, Linhares, Espírito Santo, Brasil. \\ (3) Instituto Capixaba de Pesquisa, Assistência Técnica e Extensão Rural, Venda Nova do Imigrante, Espírito Santo, Brasil. \\ (4) Universidade Federal do Espírito Santo, Centro de Ciências Agrárias, Departamento de Produção Vegetal, Alegre, Espírito Santo, Brasil. \\ * Autor correspondente. \\ E-mail: eduardo.mendonca@ufes.br
}

\section{RESUMO}

A produção de café conilon em sistemas de manejo orgânico tem aumentado no Estado do Espírito Santo. Porém, faltam informações sobre o impacto desse manejo sobre os estoques de carbono e nitrogênio do solo. Este trabalho teve como objetivo avaliar o efeito da adubação orgânica sobre os estoques de $\mathrm{C}$ e $\mathrm{N}$ e a densidade do solo (Ds) em agrossistema de café conilon. $O$ experimento foi implantado em lavoura localizada no município de Linhares, ES, no delineamento em blocos casualizados com distribuição fatorial $2 \times 2 \times 5$, com três repetições, sendo os fatores: dois compostos orgânicos; presença e ausência da leguminosa feijão-de-porco nas entrelinhas; e cinco proporções de cada composto em substituição à adubação mineral recomendada $(0 ; 25 ; 50 ; 75$; e $100 \%)$. Cada repetição foi formada por amostragem de solo sob a copa de uma planta em parcela com 30 cafeeiros. Os compostos foram: composto 1 , preparado com capim-elefante e palha de café na proporção 1:1 (v:v); e composto 2, preparado com capim-elefante, palha de café e cama de frango na proporção 2:1:1 (v:v:v). As coletas de solo foram realizadas 240 dias após a adubação (240DAPA) do $1^{\circ}$ ano agrícola e aos 30 dias após a $1^{\mathrm{a}}$ etapa da adubação (30DAPA) do $2^{\circ}$ ano agrícola. $O$ uso de composto na adubação do cafeeiro acarretou redução da Ds de aproximadamente $13 \%$. O incremento das proporções de compostos na adubação aumentou o teor e o estoque de $\mathrm{C}$ e $\mathrm{N}$ do solo aos 30DAPA do $2^{\circ}$ ano agrícola. Houve acréscimos de 11 e $0,4 \mathrm{Mg} \mathrm{ha}^{-1}$ para o estoque de $\mathrm{C} \mathrm{e} \mathrm{N}$, respectivamente, para 
cafeeiros adubados com $100 \%$ de composto 1 , em relação à adubação mineral. A adubação com composto é alternativa para aumentar os estoques de $\mathrm{C}$ e $\mathrm{N}$ no agrossistema de conilon.

Palavras-chave: compostagem, relação C/N, Argissolo.

\title{
ABSTRACT: SOIL NITROGEN AND CARBON STOCKS, AND SOIL BULK DENSITY IN ORGANIC FERTILIZATION SYSTEMS OF CONILON COFFEE
}

\begin{abstract}
Production of Conilon coffee under organic management systems has increased in the State of Espirito Santo, Brazil. However, information is lacking in regard to the impact of these management practices on soil carbon and nitrogen stocks. The aim of this study was to evaluate the effect of organic fertilization on $C$ and $N$ stocks and soil bulk density $(B d)$ in a Conilon coffee agrosystem. A field experiment was carried out in Linhares, ES, in a randomized block design in a $2 \times 2 \times 5$ factorial arrangement, with three replications. The factors were: two organic composts; presence and absence of the jackbean legume between the rows; and five different proportions of each organic compost $(0,25,50,75$, and $100 \%)$ to substitute the recommended mineral fertilization. Each replicate consisted of 30 coffee plants. Soil samples were collected under the canopy of each plant. The organic composts were compound 1, prepared from elephant grass and coffee straw in a 1:1 ratio (v:v); and compound 2, prepared from elephant grass, coffee straw, and chicken litter in a 2:1:1 ratio (v:v:v). Soil samples were taken 240 days after fertilization (240DAF) in the $1^{\text {st }}$ crop year and 30 days after the $1^{\text {st }}$ stage of fertilization (30DAF) in the $2^{\text {nd }}$ crop year. The use of organic compounds to fertilize coffee led to a decrease in $\mathrm{Bd}$ of approximately $13 \%$. The increase in the proportion of organic compounds in fertilization increased the content and stock of $C$ and $N$ in the soil at 30 days after fertilization in the $2^{\text {nd }}$ crop year. There were increases of 11 and $0.4 \mathrm{Mg} \mathrm{ha}^{-1}$ for the stock of $C$ and $N$, respectively, for coffee plants fertilized with $100 \%$ of compound 1 , in relation to mineral fertilization. Fertilization with organic compounds is an alternative for increasing $C$ and $N$ stocks in agrosystems of conilon coffee.
\end{abstract}

Keywords: composting, $C / N$ ratio, Ultisol.

\section{INTRODUÇÃO}

O café conilon (Coffea canephora Pierre ex Froehner) é produzido em larga escala no norte do Espírito Santo, o que eleva esse Estado à posição de destaque na sua produção. Em razão do alto potencial produtivo do cafeeiro, sua adubação geralmente é realizada com fertilizantes minerais de alta solubilidade (Prezotti et al., 2007). Entretanto, o uso desses fertilizantes minerais, sem calagem e adubação orgânica, pode reduzir a fertilidade do solo (Theodoro et al., 2003). Em Latossolo Vermelho-Amarelo sob lavoura de café conilon, foi verificado que a adubação anual com 450, 150 e $450 \mathrm{~kg} \mathrm{ha}^{-1}$ de $\mathrm{N}, \mathrm{P}_{2} \mathrm{O}_{5}$ e $\mathrm{K}_{2} \mathrm{O}$, respectivamente, na forma de ureia, superfosfato triplo e cloreto de potássio, reduziu o $\mathrm{pH}$ do solo e aumentou os teores de $\mathrm{Al}^{3+} \mathrm{e}$ $\mathrm{H}+\mathrm{Al}$, em relação ao solo não adubado (Guarçoni, 2011).

A matéria orgânica do solo (MOS) em sistemas tropicais é um componente de extrema importância, já que esses solos possuem avançado grau de intemperismo e baixa fertilidade natural (Silva e Mendonça, 2007). Ademais, o solo é o principal reservatório de $\mathrm{C}$ em ambiente terrestre, apresentando estoques superiores de $\mathrm{C}$ em relação à cobertura vegetal.
Manejos inadequados do solo potencializam a mineralização da MOS, aumentando a emissão de gases de efeito estufa para a atmosfera. Porém, manejos com base na ciclagem de matéria orgânica podem aumentar significativamente os estoques de $\mathrm{C}$ ao longo do tempo (Souza et al., 2012). Esses autores monitoraram o estoque de $\mathrm{C}$ em um sistema orgânico de produção ao longo de 10 anos em 12 unidades de solo verificaram acúmulo de $23,62 \mathrm{Mg} \mathrm{ha}^{-1}$ de C ao final desse período.

Em estudo de 16 anos em sistemas adubados com composto orgânico, Leite et al. (2003) obtiveram estoques de $\mathrm{C}$ variando de $18,87 \mathrm{Mg} \mathrm{ha}^{-1}$ na dose de $0 \mathrm{~m}^{3} \mathrm{ha}^{-1}$ de composto a $26,50 \mathrm{Mg} \mathrm{ha}^{-1}$ na dose de $40 \mathrm{~m}^{3} \mathrm{ha}^{-1}$ de composto na profundidade de 0,00-0,10 m. Para a mesma profundidade, os estoques de $\mathrm{N}$ foram de $1,54 \mathrm{Mg} \mathrm{ha}^{-1}$ na dose de $0 \mathrm{~m}^{3} \mathrm{ha}^{-1}$ de composto a $2,11 \mathrm{Mg} \mathrm{ha}^{-1}$ na dose de $40 \mathrm{~m}^{3} \mathrm{ha}^{-1}$ de composto.

O emprego de adubos minerais nitrogenados pode acelerar o processo de emissão de gases de efeito estufa, uma vez que em contato com o solo esses passam por reações mediadas por microrganismos que podem levar à formação de $\mathrm{N}_{2} \mathrm{O}$ (Teixeira et al., 2006). Em trabalho de campo com a cultura da cana-de-açúcar, testando doses de 60, 90, 120 e $180 \mathrm{~kg} \mathrm{ha}^{-1}$ de N, Signor (2010) observou maiores 
emissões de $\mathrm{N}_{2} \mathrm{O}$ para o nitrato de amônio em maiores doses. Assim, o uso de fontes orgânicas para suprimento de $\mathrm{N}$ do cafeeiro pode reduzir essa taxa de emissão, favorecendo a manutenção da fertilidade do solo.

A MOS interfere diretamente na formação e estabilidade de agregação do solo, que por sua vez influi sobre a densidade e a porosidade, entre outros atributos (Silva e Mendonça, 2007). Reinert et al. (2008) demonstraram em um Argissolo Vermelho que o limite crítico de densidade para o crescimento normal da cobertura vegetal foi de $1,75 \mathrm{Mg} \mathrm{m}^{-3}$.

Por causa da ausência de revolvimento, maiores valores de densidade do solo (Ds) foram obtidos em sistemas de plantio direto (sobre resíduos de mucuna, sorgo e milheto) no início do ciclo da cultura de mandioca, sendo significativamente superiores $(p<0,05)$ aos verificados no sistema sob preparo convencional (Silva et al., 2008). No entanto, a Ds (camada de 0,00-0,10 m) diminuiu significativamente $(\mathrm{p}<0,05)$ com o aumento de doses de lodo de esgoto, variando de 1,21 a $1,13 \mathrm{Mg} \mathrm{m}^{-3}$ (Boeira e Souza, 2007).

Trabalhos de adubação orgânica com a espécie Coffea arabica L. podem ser encontrados na literatura (Araújo, et al., 2007; 2008). Comparativamente, estudos nesse sentido com a espécie $C$. canephora ainda são incipientes (Partelli et al., 2009). O objetivo deste estudo foi avaliar o efeito de manejos de adubação orgânica sobre os estoques de C e N e a densidade do solo em um agrossistema de café conilon no Estado do Espírito Santo.

\section{MATERIAL E MÉTODOS}

O estudo foi conduzido em lavoura de café conilon (com irrigação por aspersão) localizada em propriedade de base familiar no distrito Córrego do Farias, Linhares, ES (19² 15’ 67” S e $40^{\circ} 01^{\prime} 93$ " O). A área da lavoura selecionada possui 0,75 ha e quatro anos de idade com espaçamento de $3,0 \times 1,2 \mathrm{~m}$, com os clones $12 \mathrm{~V}$ - componente da variedade "Vitória Incaper 8142" - e G 35 da empresa Verdebras. O solo foi classificado como um Argissolo Vermelho-Amarelo Distrófico, formado sobre os sedimentos da Formação Barreiras (Embrapa, 2006). Aa análises granulométrica e química da área foram realizadas previamente na profundidade de 0,00-0,20 m: textura franco-arenosa (794, 46, $160 \mathrm{~g} \mathrm{~kg}^{-1}$ para areia total, silte e argila, respectivamente); $\mathrm{pH} 5,6 ; 19 \mathrm{~g} \mathrm{~kg}^{-1}$ de matéria orgânica; $7 \mathrm{mg} \mathrm{dm}^{-3} \mathrm{de} \mathrm{P} ; 44 \mathrm{mg} \mathrm{dm}^{-3} \mathrm{de} \mathrm{K} ; 1,3 \mathrm{cmol}_{\mathrm{c}}$ $\mathrm{dm}^{-3}$ de Ca; 0,3 $\mathrm{cmol}_{\mathrm{c}} \mathrm{dm}^{-3} \mathrm{de} \mathrm{Mg} ; 0,1 \mathrm{cmol}_{\mathrm{c}} \mathrm{dm}^{-3} \mathrm{de}$ Al; $2,1 \mathrm{cmol}_{\mathrm{c}} \mathrm{dm}^{-3} \mathrm{de} \mathrm{H}+\mathrm{Al} ; 1,7 \mathrm{cmol}_{\mathrm{c}} \mathrm{dm}^{-3}$ de soma de bases (SB); e 44,9 \% de saturação por bases (V) (Embrapa, 1997). Antes da implantação do experimento, foi feita calagem por meio do método da saturação por bases, de forma a elevá-la para 70 \% (Prezotti et al., 2007).

O experimento foi montado num esquema fatorial $2 \times 2 \times 5$, sendo: "composto orgânico" em dois níveis; "leguminosa", em dois níveis (presença e ausência); e "proporções de cada composto", em cinco níveis (0; 25; 50; 75; e $100 \%)$ num delineamento em blocos casualizados, com três repetições. Cada repetição foi formada por amostragem de solo sob a copa de uma planta em parcela com 30 cafeeiros. Os compostos utilizados foram: composto $1(\mathrm{C} 1)$, preparado com a mistura de capim-elefante (Pennisetum purpureum Schumach) e palha de café, na proporção 1:1 (v:v); e composto 2 (C2), preparado pela mistura de capim-elefante, palha de café e cama de frango, na proporção 2:1:1 (v:v:v). Realizou-se a montagem das leiras de composto no mesmo dia do corte do capim. Para a montagem do composto 1, fez-se empilhamento alternado dos resíduos vegetais por camadas de 0,50 m de altura. Para o composto 2, as camadas foram dispostas com alturas de $0,50 \mathrm{~m}$, para o capim; e $0,25 \mathrm{~m}$, para a palha de café e cama de frango. Efetuou-se apenas um reviramento manual aos 45 dias após a montagem das leiras. Constatado o término da compostagem por meio de características físicas, amostras foram retiradas e encaminhadas para análise química no Laboratório de Análises de Solos e Planta do Incaper/CRDR-CS (Quadro 1).

Quadro 1. Caracterização química (em base seca) do composto 1 (C1) e composto 2 (C2) do primeiro e segundo ano agrícola, aos 120 dias após a montagem das leiras

\begin{tabular}{|c|c|c|c|c|c|c|c|c|c|c|c|c|c|c|c|}
\hline Tipo & Umidade $^{(1)}$ & $\mathrm{MO}^{(2)}$ & $\mathrm{C} / \mathrm{N}$ & $\mathrm{pH}\left(\mathrm{CaCl}_{2}\right)$ & $\mathbf{N}$ & $\mathbf{P}$ & $\mathbf{K}$ & $\mathbf{C a}$ & Mg & $\mathbf{S}$ & $\mathbf{Z n}$ & $\mathbf{F e}$ & Mn & $\mathbf{C u}$ & B \\
\hline & \multicolumn{2}{|l|}{$\%$} & & & \multicolumn{6}{|c|}{ dag $\mathrm{kg}^{-1}$} & \multicolumn{5}{|c|}{$\mathrm{mg} \mathrm{kg}^{-1}$} \\
\hline & \multicolumn{15}{|c|}{$1^{\circ}$ ano agrícola (2009/2010) } \\
\hline $\mathrm{C} 1$ & 64,0 & 68,6 & 23 & 7,6 & 1,50 & 0,30 & 1,73 & 0,63 & 0,16 & 0,14 & 21 & 5.111 & 63 & 28 & 23 \\
\hline \multirow[t]{2}{*}{$\mathrm{C} 2$} & 59,5 & 62,8 & 10 & 7,1 & 3,05 & 3,55 & 3,09 & 3,56 & 0,75 & 0,37 & 406 & 3.115 & 490 & 203 & 37 \\
\hline & \multicolumn{15}{|c|}{$2^{\circ}$ ano agrícola $(2010 / 2011)$} \\
\hline $\mathrm{C} 1$ & & 49,4 & 14 & 7,2 & 1,79 & 2,17 & 2,11 & 0,96 & 0,15 & 0,22 & 30 & - & 81 & 31 & 41 \\
\hline $\mathrm{C} 2$ & 39,4 & 51,6 & 12 & 6,8 & 2,31 & 3,63 & 2,86 & 4,17 & 0,51 & 0,35 & 305 & - & 429 & 175 & 37 \\
\hline
\end{tabular}

(1) Umidade dos compostos orgânicos; ${ }^{(2)}$ MO: matéria orgânica. 
O feijão-de-porco (Canavalia ensiformis) foi semeado manualmente nas entrelinhas no $1^{\circ}$ e $2^{\circ}$ anos agrícolas em 11/2009 e 01/2011. Para o plantio, foi utilizado o espaçamento de $1 \mathrm{~m}$ a partir do caule do cafeeiro e $0,50 \mathrm{~m}$ entre linhas (totalizando três linhas de leguminosas). Para a semeadura, utilizaram-se oito sementes por metro linear de sulco. $\mathrm{O}$ corte foi realizado aos 90 dias após o plantio na fase de florescimento, sendo a palhada mantida em cobertura.

Para o $1^{\circ}$ e $2^{\circ}$ anos agrícolas, 2009/2010 e 2010/2011, respectivamente, o tratamento com adição de nutrientes de fonte exclusivamente mineral (testemunha ou $0 \%$ de composto orgânico) consistiu na aplicação de $380 \mathrm{~kg} \mathrm{ha}^{-1} \mathrm{ano}^{-1}$ de $\mathrm{N}$ na forma de sulfato de amônio para produtividade esperada de 51-70 sacas ha ${ }^{-1}$ ano $^{-1}$ (Prezotti et al., 2007). Para a adubação com $\mathrm{P}$ e $\mathrm{K}$, no $1^{\circ}$ ano, foram utilizados $60 \mathrm{~kg} \mathrm{ha} \mathrm{h}^{-1}$ de $\mathrm{P}_{2} \mathrm{O}_{5}$ e $350 \mathrm{~kg} \mathrm{ha}^{-1}$ de $\mathrm{K}_{2} \mathrm{O}$ na forma de superfosfato simples e cloreto de potássio, respectivamente (Prezotti et al., 2007). No $2^{\circ}$ ano, em razão do efeito residual da adubação do $1^{\circ}$ ano, a adubação de $\mathrm{P}$ e $\mathrm{K}$ foi efetuada com base no efeito residual do $1^{\circ}$ ano e a produtividade esperada (Prezotti et al., 2007). Os tratamentos com fontes orgânicas foram determinados a partir do teor de $\mathrm{N}$ dos compostos orgânicos. Para o $1^{\circ}$ ano agrícola, no tratamento de fonte exclusivamente orgânica (100 \% de composto orgânico), foram aplicados $25,33 \mathrm{Mg} \mathrm{ha}^{-1}$ do composto 1 e $12,50 \mathrm{Mg} \mathrm{ha}^{-1}$ do composto 2 (em base úmida). Para o $2^{\circ}$ ano, o tratamento consistiu na aplicação de $42,44 \mathrm{Mg} \mathrm{ha}^{-1}$ do composto 1 e $27,40 \mathrm{Mg} \mathrm{ha}^{-1}$ do composto 2 (em base úmida). No $1^{\circ}$ ano, a umidade dos compostos não foi utilizada na correção dos cálculos de adubação. No $2^{\circ}$ ano, a umidade de $51 \%$ do composto 1 e a de $39 \%$ do composto 2 foi levada em consideração. Nas proporções 25, 50 e $75 \%$ das doses de composto orgânico, a adubação foi combinada com fontes minerais citadas anteriormente. Desse modo, para 25,50 e $75 \%$ de composto orgânico, foram utilizados 75,50 e $25 \%$ de fonte mineral, respectivamente. Os adubos foram aplicados na projeção da copa e ao redor de toda a planta.

No $1^{\circ}$ ano agrícola, a adubação foi parcelada em quatro etapas: a $1^{\mathrm{a}}$ (20 \% do adubo), em 11/2009; a $2^{\mathrm{a}}$ ( $20 \%$ do adubo), em 12/2009; a $3^{\text {a }}$ (20\% do adubo), em 03/2010; e a $4^{\mathrm{a}}$ (40\% do adubo), em 04/2010. No $2^{\mathrm{a}}$ ano, a adubação foi parcelada em duas etapas: a $1^{\text {a }}$ (50\% do adubo), em 01/2011; e a $2^{\text {a }}$ (50\% do adubo), em 04/2011.

Foram avaliados densidade do solo (Ds), carbono orgânico total (COT) e nitrogênio total (NT) aos 240 dias após a adubação (240DAPA) do $1^{\circ}$ ano agrícola e aos 30 dias após a $1^{\text {a }}$ etapa da adubação (30DAPA) do $2^{\circ}$ ano agrícola. Para isso, foi escolhida uma planta ao acaso por parcela e aberta trincheira no solo (abaixo da copa) destinada à coleta de amostras com estrutura preservada - para a Ds - e amostras com estrutura alterada - para a determinação do COT e NT. Aos 240DAPA, foram retiradas amostras nas profundidades de 0,00-0,05; 0,05-0,10;0,10-0,20 e 0,20-0,40 m. Aos 30DAPA, a amostragem foi realizada apenas na profundidade de 0,00-0,05 m. A coleta de amostra preservada de solo foi feita com anel metálico de volume conhecido e com auxílio de amostrador de Uhland. O material foi levado à estufa $\left(105^{\circ} \mathrm{C}\right)$ para eliminar a umidade e, posteriormente, foi pesado. A Ds foi determinada dividindo a massa seca do solo pelo volume do anel.

O teor de COT no solo foi determinado pelo método proposto por Yeomans e Breemner (1988). O NT foi determinado pelo método de Kjeldahl, segundo Tedesco et al. (1995). Foi calculado o estoque de carbono (ESTC), utilizando-se a equação 1:

$\mathrm{ESTC}=(\mathrm{CO} \times \mathrm{Ds} \times \mathrm{h}) / 10$

Eq. 1

em que ESTC é o estoque de C orgânico em determinada profundidade $\left(\mathrm{Mg} \mathrm{ha}^{-1}\right)$; $\mathrm{CO}$, o teor de $\mathrm{C}$ orgânico total na profundidade amostrada ( $\left.\mathrm{g} \mathrm{kg}^{-1}\right)$; Ds, a densidade do solo da camada estudada $\left(\mathrm{Mg} \mathrm{m}^{-3}\right) ; \mathrm{h}$, a espessura da camada considerada (m).

O estoque de nitrogênio (ESTN) foi calculado usando-se a equação 2 :

$\mathrm{ESTN}=(\mathrm{NT} \times \mathrm{Ds} \times \mathrm{h}) / 10$

Eq. 2

em que ESTN é o estoque de nitrogênio em determinada profundidade $\left(\mathrm{Mg} \mathrm{ha}^{-1}\right)$; NT, o teor de $\mathrm{N}$ total na profundidade amostrada $\left(\mathrm{g} \mathrm{kg}^{-1}\right)$; Ds, a densidade do solo da camada estudada $\left(\mathrm{Mg} \mathrm{m}^{-3}\right) ; \mathrm{h}$, a espessura da camada considerada (m).

Para verificar a normalidade e homogeneidade de variância, os dados foram submetidos aos testes de Lilliefors e Bartlett e, em seguida, à análise de variância $(\mathrm{p}<0,10)$, utilizando-se o software SISVAR. Utilizaram-se o teste de comparação de médias de Tukey $(p<0,10)$ para os fatores qualitativos (leguminosa e compostos) e a análise de regressão para o fator quantitativo (proporções dos compostos). Os modelos de regressão foram escolhidos por meio dos coeficientes, utilizando-se o teste "t" de Student a $10 \%$. Optou-se por utilizar o nível de $10 \%$ de significância em razão da alta variabilidade do solo, característica de experimentos conduzidos em campo.

\section{RESULTADOS E DISCUSSÃO}

\section{Ds, ESTC e ESTN aos 240 dias após a adubação (240DAPA) do $1^{\circ}$ ano agrícola}

O desdobramento da interação tripla da análise de variância demonstrou que houve efeito significativo $(\mathrm{p}<0,10)$ de tratamentos (tipo de composto e proporções de composto) apenas para a Ds na camada de 0,00-0,05 m. Para as demais variáveis (Estoques de $\mathrm{C}$ e $\mathrm{N}$ ) e profundidades analisadas 
(0,05-0,10; 0,10-0,20 e 0,20-0,40 m), não houve efeitos de tratamentos $(p>0,10)$.

Com o aumento das proporções do composto 1 (C1), observou-se redução linear da Ds na presença e ausência da leguminosa (Figura 1). Assim, diferentemente do C2, o aporte de matéria orgânica via $\mathrm{C} 1$ auxiliou na diminuição da Ds conforme foi verificada a influência da matéria orgânica sobre esse atributo em outros estudos (Braida et al., 2006; Rivenshield e Bassuk, 2007). Estudando agrossistemas de cultivo de café arábica e sistema natural sob Latossolo Vermelho-Amarelo, Nunes et al. (2010) verificaram que o agrossistema com 22 anos de cultivo (profundidade de 0,00-0,10 m) apresentou valor de Ds significativamente $(p<0,05)$ superior $\left(1,27 \mathrm{Mg} \mathrm{m}^{-3}\right)$, quando comparado ao da área de mata de 40 anos utilizada como referência $\left(0,98 \mathrm{Mg} \mathrm{m}^{-3}\right)$. Embasados na literatura, esses autores atribuíram o aumento da Ds à retirada da vegetação espontânea nas entrelinhas do cafeeiro, por meio da aplicação de herbicidas, que contribuía para o aporte e a manutenção da matéria orgânica.

Nas proporções de 25 e 100 \% na ausência da leguminosa, o C1 também apresentou menores valores de Ds em relação ao composto C2 (Figura $2 b$ ). $\mathrm{O} \mathrm{C} 1$ evidenciou relação $\mathrm{C} / \mathrm{N}$ maior comparado ao $\mathrm{C} 2$ no $1^{\circ}$ ano agrícola (Quadro 1 ), o que pode ter contribuído para o compartimento matéria orgânica leve do solo (Silva e Mendonça, 2007), favorecendo a reestruturação e a diminuição da Ds (Bayer e Mielniczuk, 2008). Além disso, em geral, o aporte inicial de $\mathrm{C}$ via $\mathrm{C} 1$ no $1^{\circ}$ ano agrícola foi $51,5 \%$ superior em relação ao $\mathrm{C} 2$, o que pode ter sido determinante para a redução da Ds. Ressalta-se que os resíduos orgânicos, de modo geral, apresentaram menor densidade, quando comparados à fração mineral; o seu aporte resulta em diminuição da densidade da mistura solo e resíduos orgânicos (Braida et al., 2006).
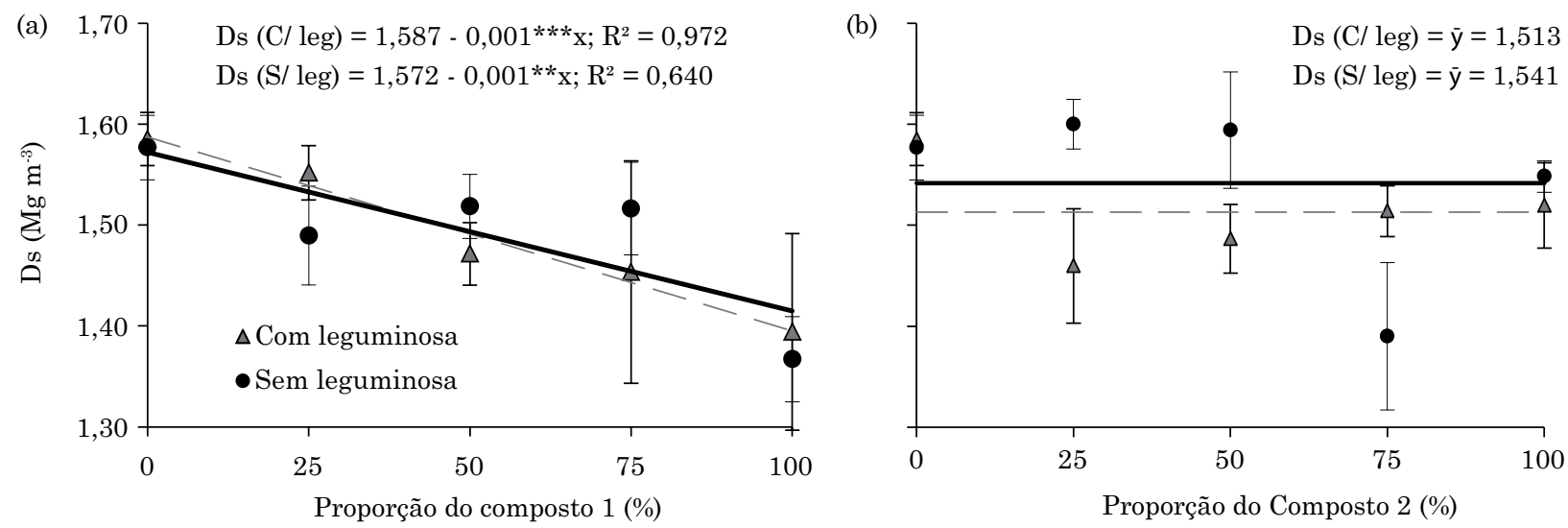

Figura 1. Densidade do solo (Ds) 240 dias após a adubação do $1^{\circ}$ ano agrícola (2009/2010) (profundidade de 0,00-0,05 m) em razão das proporções (\%) do composto 1 (a) e composto 2 (b) na presença e ausência da leguminosa (feijão-de-porco). DMS (Tukey a 10 \%) para o estudo do fator leguminosa nas proporções dos compostos: 0,11 . Barras na vertical: erro-padrão. ****, *** $\mathrm{e}$ *: significativo a 1,5 e $10 \%$, respectivamente.

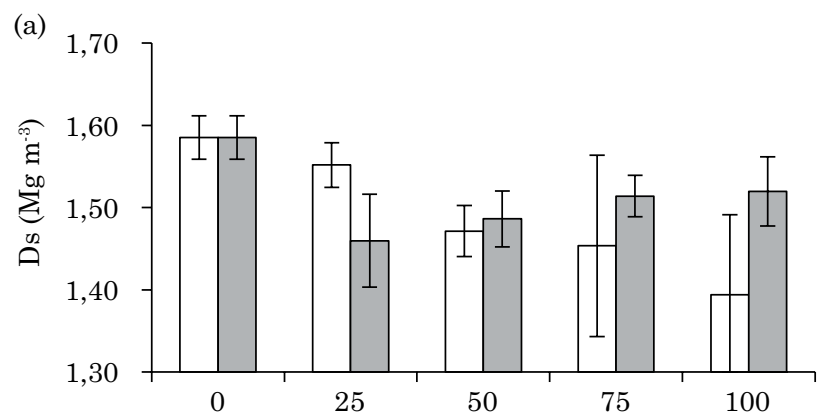

(b)

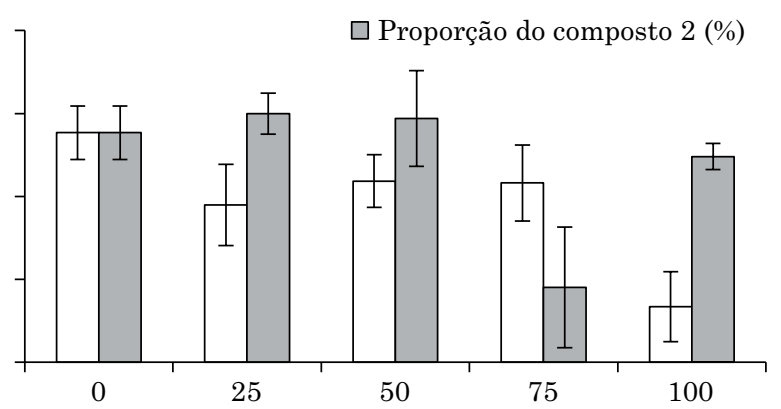

Figura 2. Densidade do solo aos 240 dias após a adubação do $1^{\circ}$ ano agrícola (2009/2010) (profundidade de 0-5 cm) em razão do tipo de composto orgânico na presença (a) e ausência (b) da leguminosa. Barras na vertical: erro-padrão. DMS (Tukey a 10 \%) para o estudo do fator “composto" em suas respectivas proporções: 0,11 . 
Não houve efeito da adubação orgânica sobre os teores de COT e NT e estoques de C e N $(\mathrm{p}>0,10)$ (dados não mostrados). O efeito não observado sobre os teores e estoques se deve às rápidas taxas de decomposição e mineralização de resíduos orgânicos nas camadas superficiais de solos tropicais (Dias et al., 2007) e, em especial, de solos com baixo teor de argila; isso é uma possível explicação para que no período em que foram feitas as amostragens não fossem detectados efeitos de tratamentos (Lepsch et al., 1982). Dependendo do manejo dos sistemas agrícolas, o tempo sugerido para encontrar diferenças em sistemas que há aplicação de resíduos orgânicos pode variar de 10 a 35 anos (Perez et al., 2004).

O ESTC, quando se utilizaram $100 \%$ do composto $\mathrm{C}$, foi $43 \mathrm{Mg} \mathrm{ha}^{-1}$ na profundidade de 0,00-0,40 m (dados não mostrados). Rangel et al. (2007) relataram ESTC médio de $83,5 \mathrm{Mg}^{\text {ha }}{ }^{-1}$ na profundidade 0,00-0,40 m de um Latossolo argiloso para cafeeiro sob manejo convencional. Assim, o baixo valor do ESTC neste estudo se deve à textura franco-arenosa, uma vez que essa não favoreceu a proteção da MOS pela agregação.
Em um Latossolo Vermelho Distrófico de textura média localizado no sul do Estado de Goiás, D’Andrea et al. (2004) relataram que os ESTCs na profundidade de 0,00-0,40 m não foram alterados significativamente pelos sistemas de manejo, sendo: pastagem de Brachiaria decumbes de 15 anos $\left(69,86 \mathrm{Mg} \mathrm{ha}^{-1}\right)$, plantio direto sob rotação milho/feijão com cinco anos sob pivô central $\left(61,07 \mathrm{Mg} \mathrm{ha}^{-1}\right)$, plantio convencional de 15 anos com grade aradora $\left(58,70 \mathrm{Mg} \mathrm{ha}^{-1}\right)$.

\section{Ds, ESTC e ESTN aos 30 dias após a $1^{\text {a }}$ etapa da adubação (30DAPA) do $2^{\circ}$ ano agrícola}

Para a profundidade de 0,00-0,05 m, o desdobramento da interação tripla da análise de variância demonstrou que houve efeito significativo $(p<0,10)$ de proporções de compostos para todas as variáveis analisadas (Ds, teores e estoques de $\mathrm{C} \mathrm{e} \mathrm{N}$ ).

Aos 30DAPA, houve decréscimos lineares da Ds com o incremento das proporções dos compostos $1 \mathrm{e}$ 2 na camada de 0,00-0,05 m (Figura 3). A aplicação dos compostos aumentou de forma linear os teores de COT e o ESTC (Figura 3). O NT e o ESTN foram maiores nas proporções de composto adicionado (\%), em comparação com a testemunha (adubação mineral) (Figura 4). Em relação à adubação
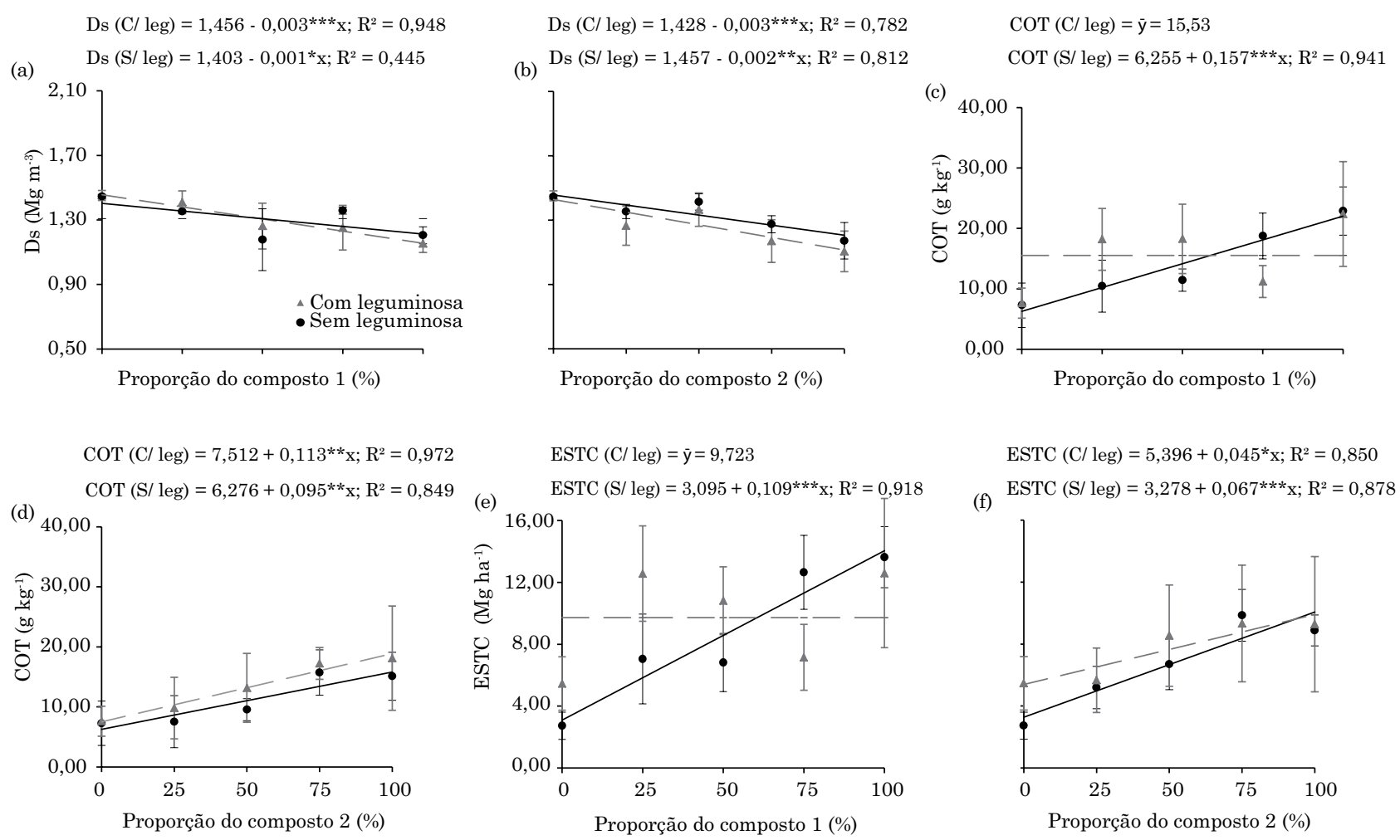

Figura 3. Densidade do solo (Ds) (a, b), carbono orgânico total (COT) (c, d) e estoque de carbono (ESTC) $(e, f)$ após 30 dias da $1^{\mathrm{a}}$ etapa da adubação do $2^{\circ}$ ano agrícola (2010/2011) (profundidade de 0,00-0,05 m) em razão das proporções (\%) do composto 1 (a) e composto 2 (b), na presença e ausência da leguminosa (feijão-de-porco). DMS (Tukey a $10 \%$ ) para o estudo do fator leguminosa nas proporções dos compostos - Ds: 0,2071; COT: 8,1925; e ESTC: 4,6575. Barras na vertical: erro- padrão. ****, ** e *: significativo a 1,5 e $10 \%$, respectivamente. 

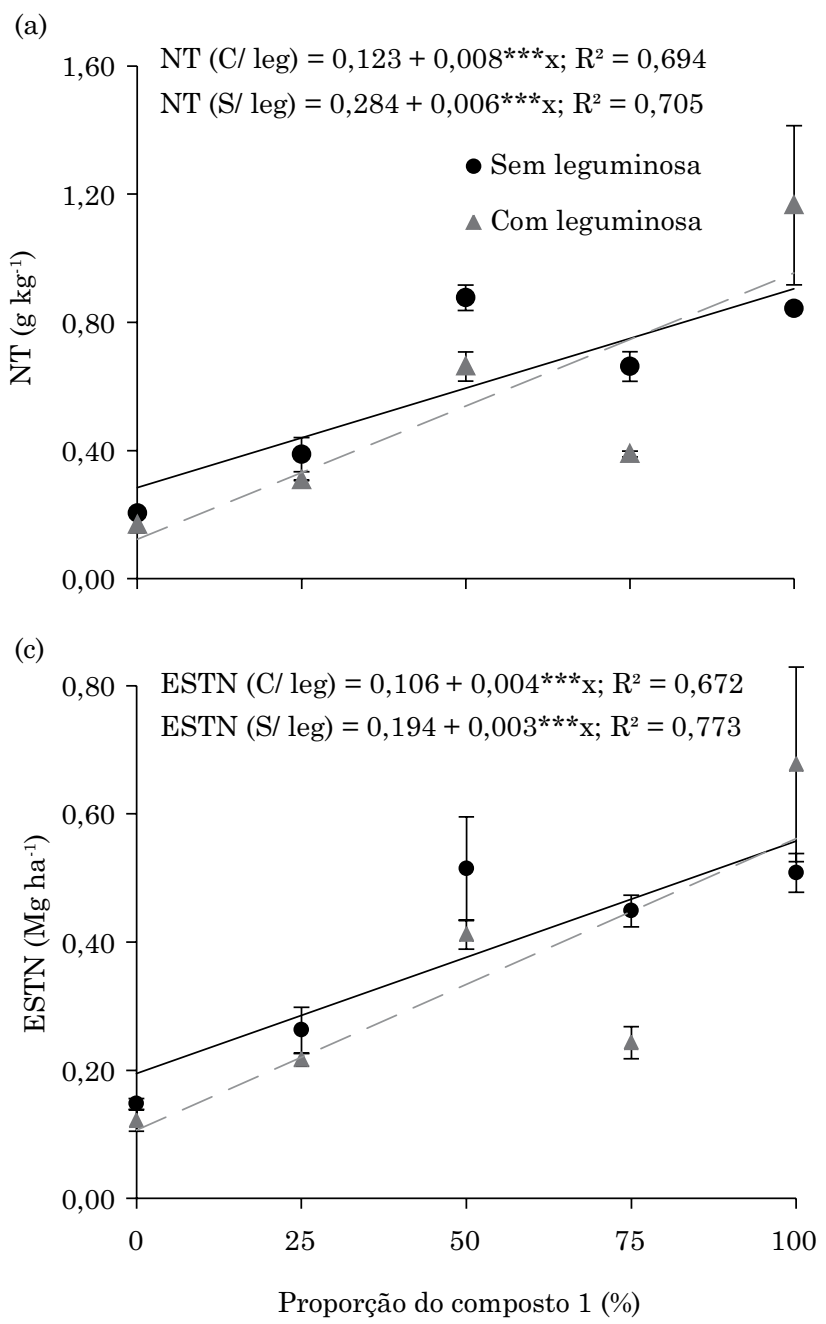

(b)

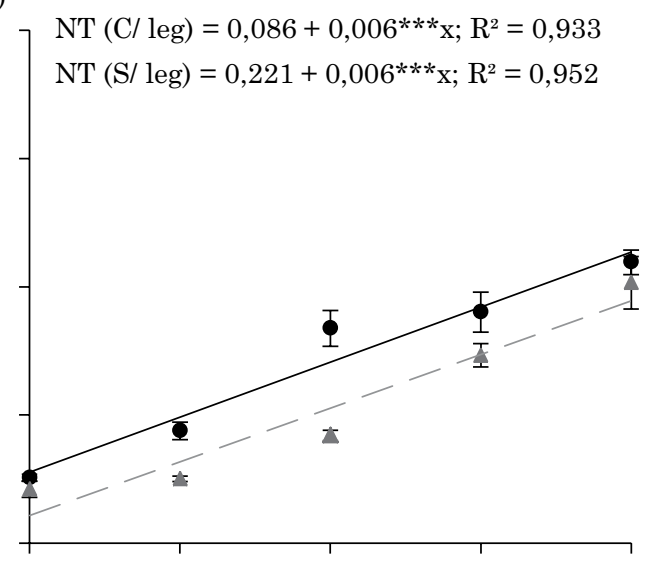

(d)

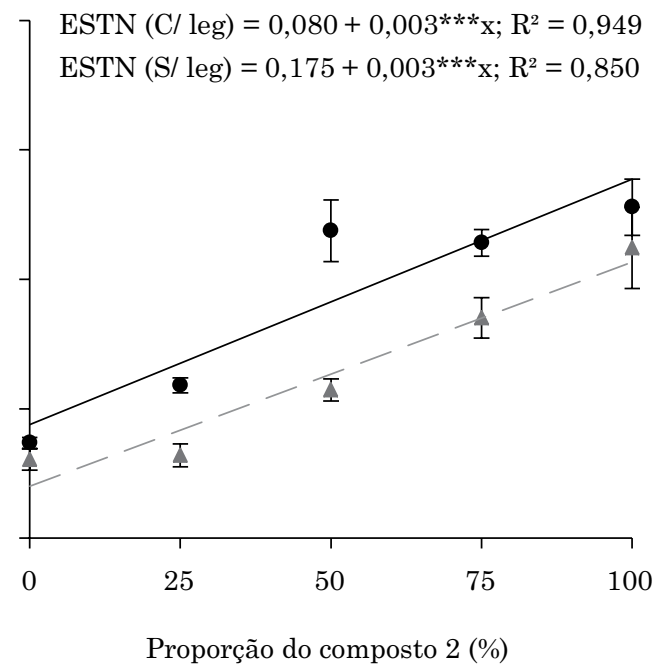

Figura 4. Nitrogênio total (NT) (a, b) e estoque de nitrogênio (ESTN) (c, d) após 30 dias da $1^{a}$ etapa da adubação do $2^{\circ}$ ano agrícola (2010/2011) (profundidade de 0,00-0,05 m) em razão das proporções (\%) do composto 1 (a) e composto 2 (b), na presença e ausência da leguminosa (feijão-de-porco). DMS (Tukey a $10 \%$ ) para o estudo do fator leguminosa nas proporções dos compostos - NT: 0,1638; ESTN: $0,1128$. Barras na vertical: erro padrão. ***, ** e *: significativo a 1,5 e $10 \%$, respectivamente.

mineral, houve acréscimos de 11 e $0,4 \mathrm{Mg}^{-1}$, respectivamente para o ESTC e ESTN, quando os cafeeiros foram adubados com $100 \%$ de C1.

$\mathrm{O}$ incremento de $\mathrm{C}$ possivelmente está relacionado às frações aportadas de matéria orgânica, principalmente a matéria orgânica particulada, que está relacionada ao material recentemente adicionado ao solo (Rossi et al., 2012). Grande parte do N nos compostos estava na forma orgânica (Sediyama et al., 2000), contribuindo para manter esse nutriente por maior período de tempo no solo, em comparação ao adubo mineral, e favorecer a formação de substâncias húmicas (Silva e Mendonça, 2007).

O maior impacto da adubação orgânica ocorreu na camada superficial, uma vez que em sistemas de cafeeiros há pouco revolvimento do solo. Aliado ao não revolvimento do solo, o cultivo de culturas perenes e o manejo orgânico são de grande importância na preservação da integridade da estrutura do solo e, consequentemente, na manutenção dos ESTC e ESTN. Culturas anuais apresentam ESTC inferiores em relação a culturas perenes em razão da maior interferência antrópica, principalmente no preparo do solo (Rangel et al., 2007).

De modo geral, dependendo do grau de estabilização e das características químicas do material, o aporte de compostos orgânicos pode favorecer a fixação e manutenção de $\mathrm{C}$ no solo e reduzir a emissão de $\mathrm{CO}_{2}$ para a atmosfera (Souza et al., 2012). Do mesmo modo, a substituição parcial e a total dos fertilizantes minerais pelo $\mathrm{N}$ orgânico também podem resultar numa diminuição na liberação de $\mathrm{N}_{2} \mathrm{O}$ (Amado et al., 2001). 


\section{CONCLUSÕES}

O composto 1 , preparado com a mistura de capim-elefante e palha de café na proporção $1: 1$ (v:v), auxiliou na diminuição em $13 \%$ da densidade do solo aos 240 dias após a adubação.

Aos 30 dias após a $1^{\mathrm{a}}$ etapa da adubação do $2^{\circ}$ ano, com o incremento das proporções do composto 2 (capim-elefante, palha de café e cama de frango, proporção 2:1:1) e composto 1 (capim-elefante e palha de café, proporção 1:1), ocorreu incremento, respectivamente, de 2,2 e 3,1 vezes $(p<0,10)$ no carbono orgânico total; e 4,7 e 5,3 vezes $(p<0,10)$ no nitrogênio total na profundidade de 0,00-0,05 m.

Em relação à adubação mineral, houve acréscimos de 11 e $0,4 \mathrm{Mg} \mathrm{ha}^{-1}$, respectivamente, para o estoque de carbono orgânico e de nitrogênio (profundidade de $0,00-0,05 \mathrm{~m}$ ), quando os cafeeiros foram adubados com $100 \%$ do composto 1 (mistura de capim-elefante e palha de café na proporção 1:1, v:v).

Não houve efeito de leguminosa (feijão de porco) $(p>0,10)$ para as variáveis estudadas por causa do curto período experimental (a leguminosa foi avaliada apenas para o efeito do plantio do $1^{\circ}$ ano agrícola) e da alta taxa de decomposição do material vegetal depositado após a roçada.

A adubação com compostos orgânicos preparados com capim-elefante e palha de café na proporção 1:1 (v:v) e com capim-elefante, palha de café e cama de frango na proporção $2: 1: 1$ (v:v:v) podem ser alternativas para aumentar o estoque de carbono orgânico e de nitrogênio em agrossistema de café conilon.

\section{AGRADECIMENTOS}

À Fundação de Amparo à Pesquisa do Espírito Santo (FAPES), pela concessão de bolsa de Pós-Graduação ao primeiro autor. Ao SAF/MDA e SECIS/MCT, por meio do CNPq, pelo apoio financeiro. Ao Instituto Capixaba de Pesquisa, Assistência Técnica e Extensão Rural, pelo apoio logístico. Ao agricultor José de Melo e sua família pelo apoio e participação.

\section{REFERÊNCIAS}

Amado TJC, Bayer C, Eltz FLF, Brum ACR. Potencial de culturas de cobertura em acumular carbono e nitrogênio no solo no plantio direto e a melhoria da qualidade ambiental. R Bras Ci Solo. 2001;25:189-97.

Araújo JBS, Carvalho GJ, Guimarães RJ, Carvalho JG. Composto orgânico e biofertilizante na nutrição do cafeeiro em formação no sistema orgânico: teores foliares. Coffee Sci. 2007;2:20-8.
Araújo JBS, Carvalho GJ, Guimarães RJ, Morais AR, Cunha RL. Composto orgânico e biofertilizante supermagro na formação de cafeeiros. Coffee Sci. 2008;3:115-23.

Bayer C, Mielniczuk J. Dinâmica e função da matéria orgânica. In: Santos GA, Silva LS, Canellas LP, Camargo FAO, editores. Fundamentos da matéria orgânica do solo: ecossistemas tropicais e subtropicais. Porto Alegre: Metrópole; 2008. p.7-18.

Boeira RC, Souza MD. Estoques de carbono orgânico e de nitrogênio, $\mathrm{pH}$ e densidade de um Latossolo após três aplicações de lodos de esgoto. R Bras Ci Solo. 2007;31:581-90.

Braida JA, Reichert JM, Veiga M, Reinert DJ. Resíduos vegetais na superfície e carbono orgânico do solo e suas relações com a densidade máxima obtida no ensaio Proctor. R Bras Ci Solo. 2006;30:605-14.

D`Andrea AF, Silva MLN, Curi N, Guilherme LRG. Estoque de carbono e nitrogênio e formas de nitrogênio mineral em um solo submetido a diferentes sistemas de manejo. Pesq Agropec Bras. 2004;39:179-86.

Dias BO, Silva CA, Soares EMB, Bettiol W. Estoque de carbono e quantificação de substâncias húmicas em Latossolo submetido à aplicação contínua de lodo de esgoto. R Bras Ci Solo. 2007;31:701-11.

Empresa Brasileira de Pesquisa Agropecuária - Embrapa. Centro Nacional de Pesquisa de Solos. Manual de métodos de análise de solo. $2^{\mathrm{a}}$.ed. Rio de Janeiro: 1997.

Empresa Brasileira de Pesquisa Agropecuária - Embrapa. Centro Nacional de Pesquisa de Solos. Sistema brasileiro de classificação de solos. Rio de Janeiro: Embrapa Solos; 2006.

Guarçoni MA. Características da fertilidade do solo influenciadas pelo plantio adensado de café conilon. Semina: Ci Agron. 2011;32:949-58.

Leite LFC, Mendonça ES, Neves JCL, Machado PLOA, Galvão JCC. Estoques totais de carbono orgânico e seus compartimentos em Argissolo sob floresta e sob milho cultivado com adubação mineral e orgânica. R Bras Ci Solo. 2003;27:821-32.

Lepsch IF, Silva NM, Espironelo A. Relação entre matéria orgânica e textura de solos sob cultivo de algodão e cana-de-açúcar, no estado de São Paulo. Bragantia. 1982;41:231-6.

Nunes LAPL, Dias LE, Jucksch I, Barros NF. Atributos físicos do solo em área de monocultivo de cafeeiro na zona da mata de Minas Gerais. Biosci J. 2010;26:71-8.

Partelli FL, Busato JG, Vieira HD, Viana AP, Canellas LP. Qualidade da matéria orgânica e distribuição do fósforo no solo de lavouras orgânicas de café Conilon. Ci Rural. 2009;39:2065-72.

Perez AM, Jucksch I, Mendonça ES, Costa LM. Impactos da implementação de um sistema agroflorestal com café na qualidade do solo. Agropec Técn. 2004;25:25-36.

Prezotti LC, Gomes JA, Dadalto GG, Oliveira JA. Manual de recomendação de calagem e adubação para o Estado do Espírito Santo - $5^{\mathrm{a}}$ aproximação. Vitória, [ES]: SEEA/Incaper/Cedagro; 2007.

Rangel OJP, Silva CA, Guimaraes PTG. Estoque e frações da matéria orgânica de Latossolo cultivado com cafeeiro em diferentes espaçamentos de plantio. R Bras Ci Solo. 2007;31:1341-53.

Reinert DJ, Albuquerque JA, Reichert JM, Aita C, Andrada MMC. Limites críticos de densidade do solo para o crescimento de raízes de plantas de cobertura em Argissolo Vermelho. R Bras Ci Solo. 2008;32:1805-16. 
Rivenshield A, Bassuk NL. Using organic amendments to decrease bulk density and increase macroporosity in compacted soils. Arboricult Urban For. 2007;33:140-6.

Rossi CQ, Pereira MG, Giácomo SG, Betta M, Polidoro JC. Frações lábeis da matéria orgânica em sistema de cultivo com palha de braquiária e sorgo. R Ci Agron. 2012;43:38-46.

Sediyama MAN, Garcia NCP, Vidigal SM, Matos AT. Nutrientes em compostos orgânicos de resíduos vegetais e dejeto de suínos. Sci Agríc. 2000;57:185-9.

Signor D. Estoques de carbono e nitrogênio e emissões de gases de efeito estufa em áreas de cana-de-açúcar na região de Piracicaba [dissertação]. Piracicaba: Escola de Agricultura Luiz de Queiroz; 2010.

Silva IR, Mendonça ES. Matéria orgânica do solo. In: Novais RF, Alvarez V VH, Barros NF, Fontes RLF, Cantarutti RB, Neves JCL, editores. Fertilidade do solo. Viçosa, MG: Sociedade Brasileira de Ciência do Solo; 2007. p.275-374.

Silva RF, Borges CD, Garib DM, Mercante FM. Atributos físicos e teor de matéria orgânica na camada superficial de um Argissolo
Vermelho cultivado com mandioca sob diferentes manejos. R Bras Ci Solo. 2008;32:2435-41.

Souza JL, Prezotti LC, Guarçoni MA. Potencial de sequestro de carbono em solos agrícolas sob manejo orgânico para redução da emissão de gases de efeito estufa. R Idesia. 2012;30:7-15.

Tedesco MJ, Gianello C, Bissani CA, Bohnen H, Volkweiss SJ. Análise de solo, plantas e outros materiais. $2^{a}$.ed. Porto Alegre: Universidade Federal do Rio Grande do Sul; 1995.

Teixeira FCP, Reinert F, Rumjanek NG, Boddey RM. Quantification of the contribution biological nitrogen fixation to Cratylia mollis using the $15 \mathrm{~N}$ natural abundance technique in the semi-arid Caatinga region of Brazil. Soil Biol Biochem. 2006;38:1989-93.

Theodoro VCA, Alvarenga MIN, Guimarães RJ, Souza CAS. Alterações químicas em solo submetido a diferentes formas de manejo do cafeeiro. R Bras Ci Solo. 2003;27:1039-47.

Yeomans JC, Bremner JMA. Rapid and precise method for routine determination of carbon in soil. Commun Soil Sci Plant Anal. 1988;19:1467-76. 